\title{
Keratomycosis caused by a Rare Fungus: Exserohilum rostratum
}

\author{
Parul Punia*, Nidhi Goel, Kausalya Kaushik and Uma Chaudhary \\ PGIMS ROHTAK, India \\ *Corresponding author
}

\begin{tabular}{|c|c|}
\hline & A B S T R A C T \\
\hline Keywords & \multirow{3}{*}{$\begin{array}{l}\text { Keratomycosis is an invasive fungal infection of the cornea which usually occurs } \\
\text { following corneal trauma by vegetative material. It is usually caused by hyaline fungus } \\
\text { such as Aspergillus, Fusarium and Acremonium, but rare case reports with phaeoid fungus } \\
\text { have been reported. We report here a case of keratomycosis caused by Exserohilum } \\
\text { rostratum. E. rostratum is a dematiaceous fungus that has been known to cause sinusiti } \\
\text { and subcutaneous infections but it has rarely been reported to be a cause of keratomycosis } \\
\text { A } 60 \text { year old man presented with decreased vision in the left eye since } 1 \text { month following } \\
\text { trauma. He was diagnosed to have corneal ulcer for which the patient underwent two } \\
\text { therapeutic keratoplasty and was given Moxifloxacin. But there was no improvement in } \\
\text { the vision. Later E. rostratum was isolated from his corneal scrapings. Topical natamycin } \\
\text { was applied and oral itraconazole was started to which the patient vision improved } \\
\text { gradually. Although E. rostratum is a rare cause of keratomycosis, but if diagnosed on } \\
\text { time and treated appropriately, it can result in complete resolution of vision. }\end{array}$} \\
\hline Article Info & \\
\hline & \\
\hline
\end{tabular}

\section{Introduction}

Keratomycosis is an invasive fungal infection causing inflammation and ulceration of the cornea. It is amongst the leading causes of visual morbidity and blindness especially in developing countries like India. ${ }^{1,2}$ It usually occurs following traumatic injury to the cornea by vegetative material contaminated with saprophytic fungus. Though the profile of mycotic keratitis agents varies according to geographical location and climate, but most of the cases reported have been caused by hyaline fungus such as Aspergillus, Fusarium etc. Rare cases have been attributed to phaeoid fungus like Alternaria, Curvularia, Bipolaris etc. $^{3}$
The phaeoid fungus, Exserohilum which is usually the causative agent of phaeohyphomycosis affecting skin, subcutaneous tissue and paranasal sinuses has only occasionally been associated with mycotic keratitis. ${ }^{3}$ Owing to rarity of this infection in the eye, there are no set guidelines for its management. Reports on treatment of mycotic keratitis with this fungus have largely been unsatisfactory, but according to some studies, early identification and treatment is a key to preserving vision in such infections.

Here we report a case of keratomycosis by Exserohilum rostratum in an old immunocompetent patient with history of trauma to his eye. 


\section{Case report}

A 60 year old man presented with decreased vision in the left eye since 1 month. He gave history of trauma to the left eye by some vegetative material while working in the fields. On ocular examination, he was diagnosed to have corneal ulcer with feathery edges. He was started on topical moxifloxacin, but the vision did not improve. He underwent two therapeutic keratoplasty, which also failed to improve the vision. His corneal scrapings and pus sample from the corneal ulcer were collected under aseptic precautions and sent to Microbiology Department. On $\mathrm{KOH}$ examination of both samples, thick, dematiacious, septate hyphae were observed. Based on $\mathrm{KOH}$ report, topical natamycin was administered to the patient. Culture on Sabouraud dextrose agar (SDA) with antibiotics showed blackish brown velvety colony with black pigment on reverse. On Lactophenol cotton blue (LPCB) preparation, phaeoid hyphae along with large, brown pigmented, thick walled, ellipsoidal multiseptate conidia with very prominent protruding truncate hilum were observed. Based on these characteristics, the isolate was identified as Exserohilum rostratum (Fig. 1). Topical natamycin was continued and oral itraconazole $100 \mathrm{mg}$ twice daily was started. The patient responded well to treatment and his vision gradually improved.

Fig.1 LPCB showing Exserohilum spp. from SDA

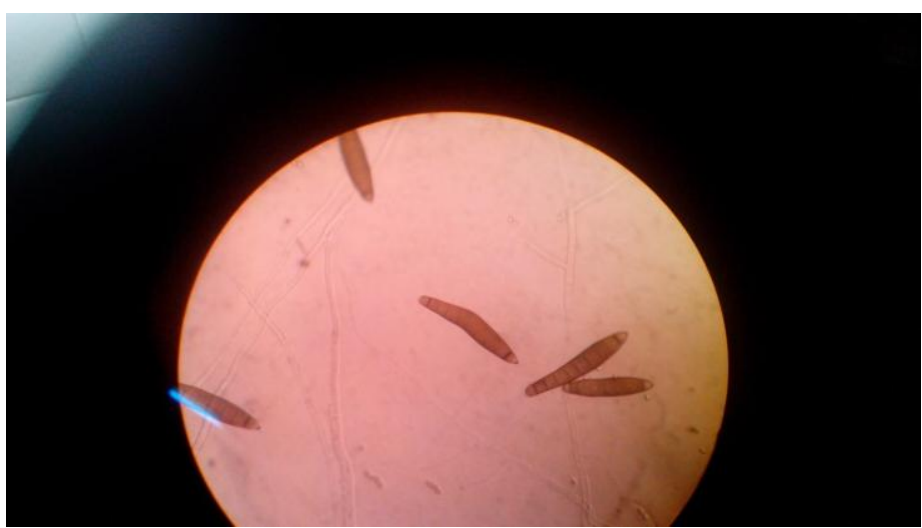

\section{Discussion}

Exserohilum spp. is a frequently encountered environmental mould present in the soil, vegetation and rotting wood. The infections caused by this fungus are commonly found in hot and humid areas such as India, Israel and the southern United States. ${ }^{4}$ This fungus is rarely pathogenic to humans and is mainly responsible for infections of skin and subcutaneous tissues. Rare case reports of keratomycosis by Exserohilum spp. have been reported. ${ }^{3}$ Various studies have documented the incidence of Exserohiulm spp. causing keratomycosis ranging from $1.3 \%-.6 .6 \% .^{5,6,7}$
Other common moulds causing keratomycosis include mainly the hyaline moulds such as Aspergillus, Fusarium, Acremonium, Penicillium.

Amongst the common risk factors associated with Exserohilum keratomycosis has been attributed to be trauma to the cornea by vegetative material, long term therapy with antibiotics and corticosteroids, with trauma being the most specific risk factor. ${ }^{8,9}$ Our patient, who is a farmer, had a history of penetrating injury to his eye by some vegetative material while working in the fields, following which he developed 
keratomycosis. Damage to the ocular tissue leading to breach in corneal epithelium permits invasion of the fungus into cornea progressing to keratomycosis. ${ }^{8}$ This patient was earlier started on antibiotics for long period which could be another factor leading to mycotic keratitis.

The genus Exserohilum has three pathological species namely, E.rostratum, E. longirostratum, and E.macginnisii. ${ }^{10}$ The most common species causing human infections is E.rostratum, which is the causative agent in this case also. All these three species have a characteristic protruding hilum and can be differentiated by their morphological features of their conidia.

Since, keratomycosis by Exserohilum spp. is rare, there is no standard treatment protocol for it. Our patient responded well to topical natamycin and systemic itraconazole. Many studies have reported good response with topical natamycin and sysyemic itraconazole. ${ }^{3,4}$ Therapeutic keratoplasty done twice in this patient did not improve the vision. A few studies have shown that therapeutic keratoplasty is not very useful in keratomycosis by Exserohilum spp. in contrast to other fungal agents causing keratomycosis. $^{8}$

Hence we conclude that, although Exserohilum rostratum is a rare cause of corneal ulcer, but it should be kept as one of the differential diagnosis if daematicious fungus is being suspected. Oral itraconazole is a promising drug in such cases. If this infection is diagnosed timely and appropriate treatment started, the vision may improve significantly.

\section{References}

1. Thomas PA. Current perspectives on ophthalmic mycoses. Clin Microbiol Rev. 2003; 16: 730-97.

2. Gopinath U, Sharma S, Garg P, Rao GN. Review of epidemiological features, microbiological diagnosis and treatment outcome of microbial keratitis; experience over a decade. Indian J Ophthalmol. 2009; 57: 2739.

3. Thomas PA. Fungal infections of the cornea. Eye. 2003; 17: 852-62.

4. Joseph NM, Kumar A, Stephen S and Kumar S. Keratomycosis caused by Exserohilum rostratum. Indian $\mathrm{J}$ of patho \& microbial. 2012; 55: 248-9.

5. Sengupta S, Rajan S, Reddy PR, Thiruvengadakrisnan K, Ravindran RD, Lalitha $\mathrm{P}$ etal. Comparative study on the incidence and outcomes of pigmented versus nonpigmented keratomycosis. Indian $\mathbf{J}$ ophthalmol. 2011; 59: 291.

6. Arora U, Gill PK, Chalotra S. Fungal profile of keratomycosis. Bombay Hosp J.2009;51:32-7.

7. Bharathi MJ, Ramakrishnan R, Vasu S, Meenakshi, Palaniappan R. Aetiological diagnosis of microbial keratitis in South Indiaa study of 118 cases. Indian J Med Microbiol. 2002; 20: 19-24.

8. Rathi H, Venugopal A, Rameshkumar G, Ramakrishnan R, Meenakshi R. Fungal keratitis caused by Exserohilum, An emerging pathogen. Cornea. 2016; 35: 644-6.

9. Rautaraya B, Sharma S, Kar S, Das S, Sahu SK. Diagnosis and treatment outcome of mycotic keratitis at a tertiary eye care center in Eastern India. BMC Ophthalmology 2011; 11: 39.

10. Peerapur BV, Rao SD, Patil S, Mantur BG. Keratomycosis due to Eserohilum rostratumA case report. Indian J Med Microbiol. 2004; 22: 126-7.

\section{How to cite this article:}

Parul Punia, Nidhi Goel, Kausalya Kaushik and Uma Chaudhary. 2019. Keratomycosis caused by a Rare Fungus: Exserohilum Rostratum. Int.J.Curr.Microbiol.App.Sci. 8(02): 938-940. doi: https://doi.org/10.20546/ijcmas.2019.802.107 